\title{
The importance of the river-estuary interface (REI) zone in estuaries
}

\author{
GC Bate ${ }^{1}$, AK Whitfield ${ }^{2}$, JB Adams ${ }^{1}$, P Huizinga ${ }^{3}$ and TH Wooldridge ${ }^{1}$ \\ ${ }^{1}$ University of Port Elizabeth, PO Box 1600, Port Elizabeth 6000, South Africa \\ ${ }^{2}$ South African Institute for Aquatic Biodiversity, Private Bag 1015, Grahamstown 6140, South Africa \\ ${ }^{3}$ CSIR, PO Box 320, Stellenbosch 7600, South Africa, South Africa
}

\begin{abstract}
A multidisciplinary and multi-institutional research programme studied the influence of river flow rate on salinity distribution and response of the biota in three Eastern Cape estuaries, South Africa. Elevated flow rates increased the size of the riverestuary interface (REI) zone $\left(<\left.10 \mathrm{~g} \cdot\right|^{-1}\right)$ both longitudinally and in volume. In the Gamtoos Estuary, a flow rate of between 0.8 and $1.2 \mathrm{~m}^{3} \cdot \mathrm{s}^{-1}$ produced a maximum phytoplankton biomass, both as concentration and total within the estuary. There was no clear relationship between measurable mineral nutrient content in the water and phytoplankton biomass, presumably because minerals are taken up rapidly by microalgae and are therefore not reflected in the water analyses. The rate of water flow and the size of the REI were shown to affect the distribution of invertebrates. Pelagic and benthic invertebrates showed distinct species assemblages along the longitudinal salinity gradient, with filter-feeding forms dominating the benthic community in the REI region. The effect of the REI zone on fish was examined in the freshwater-rich Great Fish Estuary and in the freshwater-deprived Kariega Estuary. Estuarine associated fishes responded strongly to river flow in the Great Fish Estuary but a number of these taxa were limited or absent from the Kariega Estuary. These findings are discussed in relation to the determination of the quantity and quality of water required to sustain ecologically sound estuarine ecosystems in terms of the South African National Water Act (36) of 1998.
\end{abstract}

\section{Introduction}

Observations in a number of Eastern Cape estuaries (Hilmer, 1990; Wooldridge, 1999) indicated that biological activity varies along the salinity gradient. This raised the question as to how salinity influences biological activity and whether salinity per se is the determining factor, or whether it is only correlated with high activity and diversity. This resulted in the identification by members of the Consortium for Estuarine Research and Management (CERM) of an area known as the river-estuary interface (REI) region, here defined as the sector where integrated vertical salinity values are generally less than $10 \mathrm{mg} \cdot \mathrm{l}^{-1}$.

Sediment transported into or out of the estuary is unequal over a tidal cycle. In South African estuaries, sediment load is usually greater on the incoming tide, leading to the natural tendency for the mouth to block up with marine sediments. Along the southern coast of South Africa particularly, large flood tidal deltas develop in the lower reaches of estuaries. These flood tidal deltas can extend for kilometers above the mouth in some cases. Consequently, the state of the mouth is an important determinant of the hydrological characteristics (and hence biotic response) within the estuary. Inter alia, the state of the mouth influences the extent of water exchange with the sea, vertical and horizontal salinity distribution in the water column as well as water velocity within the estuary. The state of the estuary mouth is constantly changing, ranging from a tendency to block during times of low river inflow to scour events during river flooding. Thus, the rate at which river water flows into an estuary is largely responsible for establishing specific estuarine characteristics over time.

With water being needed inland to support human needs, managing the estuarine environment translates to ensuring that sufficient freshwater is permitted to flow into estuaries to retain an

* To whom all correspondence should be addressed.

푱 041504 2397; fax: 041583 2317; e-mail: btagcb@upe.ac.za Received 24 October 2001; accepted in revised form 18 March 2002 acceptable ecological status as required by the National Water Act (No. 36) of 1998.

The purpose of the work reported here was to identify aspects of estuarine ecology that will contribute to sound decision- making with respect to the amount of water required to support natural estuarine functions, especially related to salinity distribution. This study only aimed to represent estuaries that, in their natural condition, are normally open to the sea. The scope of this paper is confined to the importance of the REI region and not to the amount of water required to keep the mouth open. Hence, only a portion of the whole study is reported here and interested readers are referred to the report compiled by Whitfield and Wood (2002) for further details. Additional information can also be obtained by reference to Bate and Adams (2000), for similar work published on the freshwater-starved Kromme Estuary.

\section{The study sites}

The main study site for this interdisciplinary project was the Gamtoos Estuary in the Eastern Cape Province, South Africa (Fig. 1). Additional sites where fish studies were undertaken were the Kariega Estuary and Great Fish Estuary.

The mouth region of the Gamtoos Estuary is shallow $(<1.5 \mathrm{~m})$ and narrow $(<50 \mathrm{~m})$ and, for the first $1.5 \mathrm{~km}$ upstream, an extensive flood tide delta has developed. Beyond the flood tide delta, the main channel deepens to $\sim 4 \mathrm{~m}$ in the middle reaches, but upstream of 8 $\mathrm{km}$ the estuary becomes progressively narrower $(<100.0 \mathrm{~m})$ and shallower $(<2.5 \mathrm{~m})$. This trend continues all the way to the tidal head $(20 \mathrm{~km})$, where water depths are usually $<1 \mathrm{~m}$.

Three major dams are situated in the catchment $\left(34450 \mathrm{~km}^{2}\right.$ in area) of the Gamtoos Estuary, and the total storage capacity of these reservoirs $\left(249 \times 10^{6} \mathrm{~m}^{3}\right)$ is equivalent to half the mean annual runoff $\left(501 \times 10^{6} \mathrm{~m}^{3}\right.$; Jezewski and Roberts 1986). The tidal reaches of the estuary extend over approximately $20 \mathrm{~km}$, though the exact position of the tidal head shifts several kilometers, depending on river scouring and the amount of freshwater entering the estuary. 


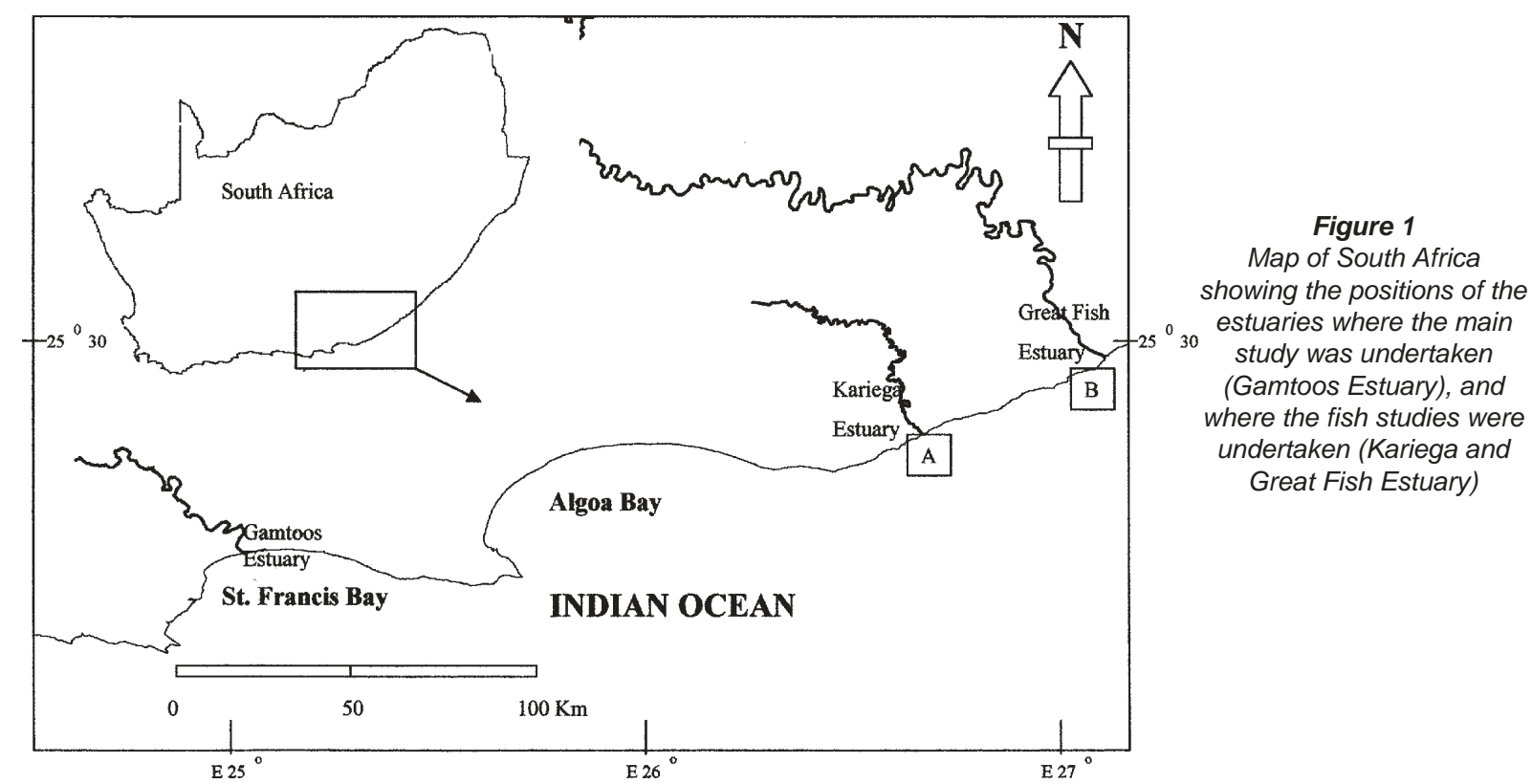

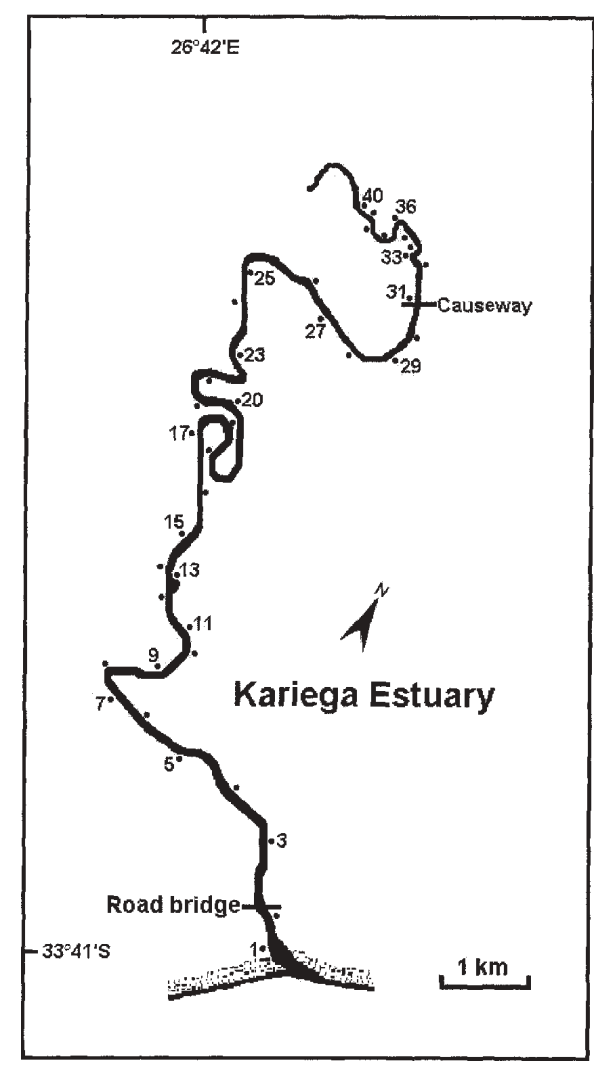

Figure 2

Map of the Kariega Estuary indicating sampling sites (after Whitfield and Wood (2002)).

The permanently open Kariega Estuary is situated on the east

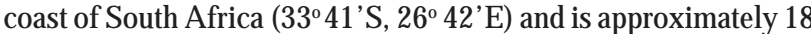
$\mathrm{km}$ long (Fig. 2). The channel in the upper reaches is narrow (40 to $60 \mathrm{~m}$ ) while in the lower reaches the estuary widens $(100 \mathrm{~m})$ and is bordered by sand flats and salt marshes (Grange, 1992). The estuary has an average midstream depth of between 2.5 and $3.5 \mathrm{~m}$.

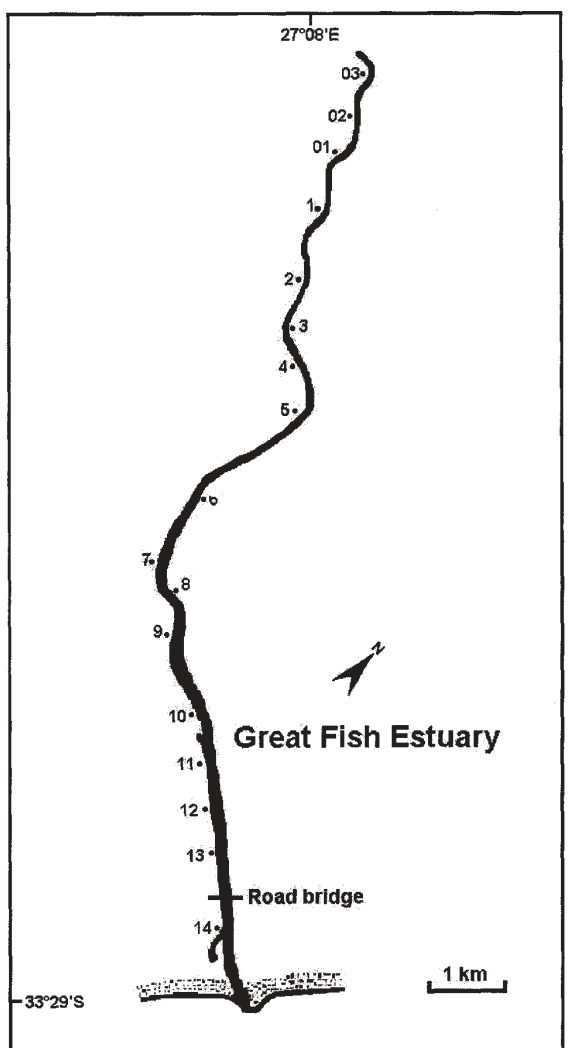

Figure 3

Map of the Great Fish River system showing the sampling sites and (inset) the position of the Great Fish River mouth (after Whitfield and Wood (2002)).

The Kariega Estuary is a marine dominated system with very little riverine influence (Fig. 3). The system is often hypersaline in the upper reaches and, apart from episodic freshwater inputs, river inflow is negligible for extended periods (Hodgson, 1987; Allanson and Read, 1995; Grange et al., 2000). This low freshwater input into the system is due to the Eastern Cape being relatively arid, which 
is exacerbated by a very poor rainfall to runoff conversion. In addition, the catchment of the Kariega Estuary is small $\left(686 \mathrm{~km}^{2}\right)$ and highly regulated by three dams and numerous farm weirs. By contrast, the marine environment has a major influence on the estuary, which is demonstrated by the 106:1 ratio of tidal prism volume to river volume (Grange et al., 2000). Even without a strong freshwater input, scouring by tidal currents is sufficient to maintain a permanent connection with the sea.

With a strong marine influence and negligible freshwater input, the salinity is usually uniformly marine $\left(35 \mathrm{~g} \cdot \mathrm{l}^{-1}\right)$ along most of the length of the estuary. The system has a low turbidity $(<10$ NTU) and is well mixed with almost no salinity or thermal stratification of the water column at any stage of the tidal cycle (Grange and Allanson, 1995).

The Great Fish Estuary $\left(33^{\circ} 28^{\prime} \mathrm{S}\right.$ and $\left.27^{\circ} 10^{\prime} \mathrm{E}\right)$ enters the Indian Ocean about half-way between Port Elizabeth and East London. Before 1975, the river was known to have had a highly variable flow regime. Periods of zero surface flow frequently occurred, causing the river to form a series of discrete pools. When these conditions persisted long enough, closure of the estuary mouth resulted (Reddering and Esterhuysen, 1982). However, in 1975 the erratic flow of this system was stabilised by the provision of water from the Orange River via an $85 \mathrm{~km}$ long tunnel. The geology of the catchment is such that considerable amounts of salts are leached from ancient marine sediments by runoff (O'Keeffe and De Moor, 1988). Consequently, the salinity level in the river can be as high as $2 \mathrm{~g} \cdot \mathrm{l}^{-1}$ but these are diluted by water from the Orange River (0.132 $\left.\mathrm{g} \cdot \mathrm{l}^{-1}\right)$ (O'Keeffe and De Moor, 1988). In addition, the river is extremely turbid (average 200 NTU) due to the highly erodable soils present in the catchment area (Laurenson, 1984).

In 1980, the tidal head was about $11 \mathrm{~km}$ from the Great Fish mouth and the furthest extent of estuarine water was only 5 to $7 \mathrm{~km}$ from the mouth (Reddering and Esterhuysen, 1982). For the period from 1992 to 1995 , the tidal head was approximately $15 \mathrm{~km}$ from the mouth and the furthest extent of saline water $\left(\left.1 \mathrm{~g} \cdot\right|^{-1}\right)$ at spring high tide ranged from 3 to $10 \mathrm{~km}$ from the mouth, varying according to river flow rate.

\section{Materials and methods}

\section{The distribution of salinity at different river flow rates in the Gamtoos Estuary}

The work undertaken on the effects of river flow on the distribution of salinity in the estuary was undertaken utilising the MIKE 11 modelling system (for details see Slinger et al., 1998). Available data on cross-sections were used to set the model up and further field data on water levels, river flow and salinity were obtained by measurements made in the estuary under natural flow conditions. These data were used to calibrate the computer model and, thereafter, the estimates of salinity distribution were determined by MIKE 11 simulation. Subsequently, these data were used in the model to estimate flow in the estuary at different positions.

Fortuitously, a flood occurred in the estuary during November 1996 while the work was in progress. This flood was large enough to remove much of the bottom sediment upstream of the estuary. The result was that after the flood, the volume of the estuary was different to what it was before. This allowed estimations to be made of the correlation between river flow, estuary volume and the distribution of salinity within the estuary for pre- and post- flood conditions. The model was also used to estimate the retention time of water within the estuary for different river flow rates. Ultimately, the model output permitted the preparation of tables of the distances from the mouth at which selected salinity concentrations would occur under different river flow conditions. In addition, the data allowed estimations to be made of the volumes of water in the estuary under different cross-sections (i.e. before and after floods) at different salinity values.

\section{Structure and dynamics of estuarine microalgae}

Ten sampling sessions took place between November 1996 and February 1998. Site 1 was near the estuary mouth within the floodtide delta and site Site 9 near the tidal head of the estuary. Further upstream was considered riverine and above the estuarine tidal influence. Data from 293 depth profiles were collected and salinity, nitrate and chlorophyll- $a$ measured. Water samples were collected using a $500 \mathrm{ml}$ pop-bottle at zero, 0.5 and $1 \mathrm{~m}$ and thereafter at $1 \mathrm{~m}$ depth intervals to the bottom, then were gravity filtered through plastic Millipore filter towers with Whatman (GF/C) glass fibre filters. The chlorophyll- $a$ was extracted by placing the filters into glass vials with $10 \mathrm{ml}$ of $95 \%$ ethanol (Merck 4111). The samples were then stored overnight at 1 to $2^{\circ} \mathrm{C}$. The contents of the vials were filtered and the light absorbance at $665 \mathrm{~nm}$ of the supernatant was determined, before and after adding two drops of $0.1 \mathrm{~N} \mathrm{HCl}$, using a GBC UV-VIS spectrophotometer. Chlorophyll- $a$ was calculated using the equation of Hilmer (1990) that had been derived from that of Nusch (1980).

Chlorophyll- $a$ from the intertidal and subtidal benthic samples was extracted at low temperature $\left(1\right.$ to $\left.2^{\circ} \mathrm{C}\right)$ overnight, then determined using high performance liquid chromatography. Chlorophyll- $a$ is expressed as the average biomass (kilograms) for the entire estuary at each flow rate. These were obtained by multiplying average site chlorophyll- $a$ concentrations $\left(\mathrm{mg} \cdot \mathrm{m}^{-2}\right)$ by the approximate area of the intertidal and subtidal regions.

\section{Structure and dynamics of invertebrate fauna}

Benthic macrofauna was sampled at 12 sites (Fig. 4) positioned at approximately $2 \mathrm{~km}$ intervals along the axis of the estuary. Sampling spanned the entire estuary from the mouth to the tidal head. Numbering of sites follows a previous study on plankton distribution (Schlacher and Wooldridge, 1996a). Five additional sites were sampled for macrofauna in this study. One was situated in the muddy, blind arm adjacent to the sandy flood tide delta, while two were located in the transition zone between the muddy and the sandy sediments of the middle reaches and two covered the tidal reaches of the upper estuary close to the tidal head.

For the purpose of this programme, a benthos survey was conducted on 4 November 1996. Data obtained in this sampling series were compared to earlier studies in 1993 and 1994. Macrobenthos sampling in this programme focused on the subtidal fauna.

At each site, three random benthic samples were collected with a Van Veen grab $\left(211 \mathrm{~cm}^{2}\right.$ sampling area), operated by hand from a small boat. To reduce effects on macrofauna density related to water depth, at each site the cross-channel position of the sampling station was adjusted so that grab samples were taken between a depth of 1.5 to $2.0 \mathrm{~m}$. Whole grab samples were immediately preserved in $10 \%$ formalin containing Rose Bengal dye. Thalassinid prawns, which burrow up to $1 \mathrm{~m}$ into the sediment, (Hanekom et al., 1988) were not effectively sampled with the Van Veen grab and this group was therefore omitted from the numerical analysis. At each site, temperature and salinity profiles of the water column were measured at $0.5 \mathrm{~m}$ depth intervals with a Valeport CTD meter. In 


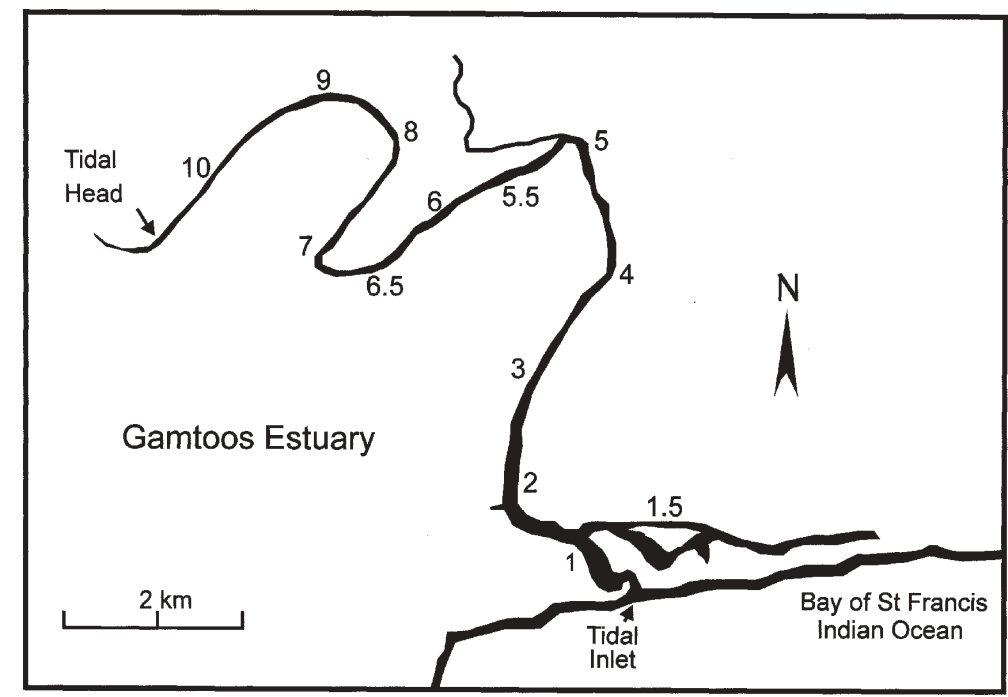

Figure 4

Invertebrate sampling sites in the Gamtoos Estuary.

The benthos was sampled at all sites, while zooplankton was samples at sites Sites 1-8 (excluding Ssites 1.5, 5.5, and 6.5). the laboratory, macrobenthos was extracted from sediment samples by repeated decantation and all individuals that were retained on a mesh of $0.25 \mathrm{~mm}$ aperture size were enumerated to the nearest identifiable taxon.

Zooplankton was sampled $2 \mathrm{~h}$ after sunset over Sites 1 to 8 (Fig. 4), where macrobenthos grabs were taken during daylight hours. The sampling protocol is detailed in Schlacher and Wooldridge (1996a). WP2-nets with a mesh size of $0.2 \mathrm{~mm}$ and fitted with Khalisco flow meters were used to sample the watercolumn. Two nets were attached to booms protruding laterally from the bow region of a small ski-boat; one net sampled just below the water surface, while the bottom-clearance of the second net was adjusted to approximately $20 \mathrm{~cm}$ above the substrate. In the laboratory, the number of plankters per tow was determined from 3 to 6 subsamples and final counts then converted to individuals per $\mathrm{m}^{3}$ using the flow-meter data. As was the case for macrobenthos, these data were compared against a medium-term data series recorded at the same sites at monthly intervals from February 1989 to March 1991, thus yielding 26 density estimates per site and species.

\section{Structure and dynamics of fish assemblages}

Two estuaries with contrasting river flow regimes were investigated. The Great Fish system was selected for this project because it receives a regular freshwater input and is navigable by boat beyond the estuarine section. This facilitated comparable sampling in both the river and estuary regions. In contrast, the Kariega Estuary had a very limited REI zone and was not navigable by boat above the estuary head region.

Sampling in the Kariega headwaters was conducted monthly from January to December 1999. The littoral zone was sampled over high tide at the upper 10 sites (Fig. 2) using a 5 x $1.5 \mathrm{~m}$ anchovy seine net (5 $\mathrm{mm}$ bar mesh). Each seine net haul swept an estimated $35.0 \mathrm{~m}^{2}$ area. All fish were fixed in $10 \%$ formalin on site and transported back to the laboratory for analysis.

For the Kariega fish distribution study, samples were collected during January, May, July and October 1999. Within each season, all 40 sites were seined over two consecutive days using the sampling protocol described above. In addition, the percentage vegetation cover was visually assessed and water temperature, salinity, turbidity, percentage oxygen concentration and $\mathrm{pH}$ were measured at each site.
A small seine net ( $5 \times 1 \mathrm{~m}$ and $0.5 \mathrm{~mm}$ bar mesh size) was used from September 1994 to January 1995 at Sites 03 to 14 in the Great Fish system (Fig. 3). This seine net, which targeted small, littoral fishes, was operated by two people in water less than $75 \mathrm{~cm}$ deep and covered an estimated $25 \mathrm{~m}^{2}$ per haul. All samples were fixed on site in $10 \%$ formalin. In the laboratory, fish were identified to the lowest possible taxonomic level, measured to the nearest $\mathrm{mm}$ standard length (SL) and preserved in 60\% isopropyl alcohol.

A large seine net $(30 \times 2 \mathrm{~m}$ with a $10 \mathrm{~mm}$ bar mesh size, fitted with a bag of $5 \mathrm{~mm}$ bar mesh size) was also employed on all 14 field trips in the Great Fish system. From November 1992 until July 1994, samples were collected from sites Sites 1 to 8. For the last three trips, September 1994 to January 1995, sampling occurred at all 17 sites (Fig. 3). The net facilitated the capture of small- and medium-size classes of most species.

\section{Results}

\section{The influence of a flood on the volume of the Gamtoos} Estuary

On 21 November 1996, a large flood scoured the estuary of a considerable amount of sediment, especially in the upper reaches where at most cross-sections, the depths of the channel increased by more than $1 \mathrm{~m}$. It is difficult to quantify the effects in the lower reaches, because the 1985 and 1997 cross-sections were not all measured at the same positions. However, using the width, depth and distance between stations, an approximate volume was calculated for 1985 and post-flood in 1997 . These data show that the volume in both 1985 and 1997 was about 2.5 million $\times 10^{6} \mathrm{~m}^{3}$, with the 1997 volume just $1.3 \%$ larger. Considering the size of the 1996 flood, it is surprising that the volume differences were not greater because the maximum flow was almost $3200 \mathrm{~m}^{3} \cdot \mathrm{s}^{-1}$. However, the scouring appeared to have the effect of greatly increasing the upper portions of the estuary at the expense of the lower sections.

The influence of freshwater inflow rate on salinity distribution in the Gamtoos Estuary

\section{Simulated salinity concentrations}

Under all constant flow conditions of $0.1,0.25,0.5,1,5,10$ and $20 \mathrm{~m}^{3} \cdot \mathrm{s}^{-1}$, a salinity gradient will be present in the estuary. However, 
the salinity profiles shift downstream when flow increases. There is always a strong influence on the salinity distribution even at low river flow. The results for flow rates of $5 \mathrm{~m}^{3} \cdot \mathrm{s}^{-1}$ and higher show that most of the estuary becomes fresh upstream and that seawater intrusion takes place only in the lower $10 \mathrm{~km}$ of the estuary. This effect is even stronger at higher river flows. During a neap tide, with a flow rate of $5 \mathrm{~m}^{3} \cdot \mathrm{s}^{-1}$, salinity is only present in the lower $7 \mathrm{~km}$ of the estuary and the gradients are very steep. At a high flow rate of $20 \mathrm{~m}^{3} \cdot \mathrm{s}^{-1}$, a salinity gradient will exist only in the lower $3 \mathrm{~km}$ of the estuary during a neap tide. This indicates that at a flow rate of $20 \mathrm{~m}^{3} \cdot \mathrm{s}^{-1}$, the estuary is nearly fresh at low tide.

\section{Comparison of salinity distribution for pre- and post- flood conditions at different constant low river flows}

Salinity concentrations in the Gamtoos Estuary were measured at neap tide on 3 November 1996 to calibrate the MIKE 11 model. Only minor differences were observed between the salinity concentrations during flood and ebb tides. The intrusion of saline water extended to approximately $14 \mathrm{~km}$ upstream of the mouth. The corresponding river flow rate was estimated at $1.0 \mathrm{~m}^{3} \cdot \mathrm{s}^{-1}$. Fairly strong stratification was observed between the mouth and about 15 $\mathrm{km}$ upstream. For example, $8 \mathrm{~km}$ upstream, salinity was $>30 \mathrm{~g} \cdot \mathrm{l}^{-1}$ at the bottom while $<\left.5 \mathrm{~g} \cdot\right|^{-1}$ was measured at the surface.

Strong river flow occurred in the catchment between 3 and 11 November 1996. The effects were observed on the salinity on 11 November 1996. The results of the measurements on the flood tide show a saline intrusion to about $8 \mathrm{~km}$ upstream of the mouth. This intrusion was reduced on the ebb tide. Elevated salinity occurred approximately $8 \mathrm{~km}$ upstream on the bottom but only about $5 \mathrm{~km}$ upstream at the surface. Strong stratification was present in both profiles, e.g. on the ebb tide $2.5 \mathrm{~km}$ from the mouth, salinity was about $2 \mathrm{~g} \cdot \mathrm{l}^{-1}$ on the surface and more than $20 \mathrm{~g} \cdot \mathrm{l}^{-1}$ at $2 \mathrm{~m}$.

Model simulations were repeated for post-flood estuarine topography. A direct comparison between longitudinal profiles for pre- and post-flood conditions at different constant river flow rates showed increased intrusion of saline water following flood scouring of the estuary. This was most marked in the upper reaches of the estuary and at low flow rates $\left(0.1\right.$ to $\left.0.5 \mathrm{~m}^{3} \cdot \mathrm{s}^{-1}\right)$.

\section{River flow and REI volumes}

The work on salinity distribution was undertaken in parallel with research on the importance of salinity distributions to the ecology of the estuary. This work concentrated on the REI region, especially the position of the $10 \mathrm{~g} \cdot \mathrm{f}^{-1}$ isohaline. Not only is the determination of this position important, but the volume of water upstream of this interface is also important, as this represents the size of the habitat available for certain biotic components. Further investigations were therefore undertaken using the model to quantify the volumes of water present in the estuary below selected salinity concentrations under the different flow conditions. At both low and high tide, volume of the REI region $\left(<\left.10 \mathrm{~g} \cdot\right|^{-1}\right)$ varies from $40000 \mathrm{~m}^{3}$ at a river flow rate of $0.1 \mathrm{~m}^{3} \cdot \mathrm{s}^{-1}$ to about $700000 \mathrm{~m}^{3}$ at $1.0 \mathrm{~m}^{3} \cdot \mathrm{s}^{-1}$ and 4000 $000 \mathrm{~m}^{3}$ at a river flow rate of $20 \mathrm{~m}^{3} \cdot \mathrm{s}^{-1}$. Hence, a high river flow greatly increases the volume of the REI. This indicates that if the $\mathrm{REI}$ is an important biological region, high river flows enhance the ecological status of this portion of the estuary.

\section{Freshwater retention times in the estuary}

The retention time of river water in the estuary was visualised by modelling the way a conservative tracer behaved at different river flow rates. The theoretical tracer was present in the estuary at time zero, but none was added thereafter. Near the mouth at a flow of
$0.1 \mathrm{~m}^{3} \cdot \mathrm{s}^{-1}$, the tracer concentration, which is initially $100 \%$ at time zero, was strongly reduced within a few days because of the exchange of water with the sea. The reduction upstream is caused by the inflow of river water with a tracer concentration of zero. Highest tracer concentrations remained in the middle of the estuary between 10 and $20 \mathrm{~km}$ from the mouth. However, the concentrations in the middle of the estuary dropped to about $14 \%$ after $40 \mathrm{~d}$. At $1 \mathrm{~m}^{3} \cdot \mathrm{s}^{-1}$ a much stronger reduction in concentration was observed upstream because of the stronger river flow rate and lowered salinity levels were reached after 20,30 and $40 \mathrm{~d}$ in the whole estuary. After $40 \mathrm{~d}$, the maximum tracer levels were approximately $2 \%$ at about $7 \mathrm{~km}$ upstream of the mouth. At $5 \mathrm{~m}^{3} \cdot \mathrm{s}^{-1}$ an even stronger reduction in tracer was observed upstream because of the stronger river flow rate. Maximum levels of approximately $7 \%$ were present $8 \mathrm{~km}$ from the mouth after $10 \mathrm{~d}$ and the concentrations were below $1 \%$ in the whole estuary after $20 \mathrm{~d}$. Thus, after $40 \mathrm{~d}$ at a flow rate of $0.1 \mathrm{~m}^{3} \cdot \mathrm{s}^{-1}$ the tracer concentration had dropped to $14 \%$ in the middle estuary, while at a flow rate of $1 \mathrm{~m}^{3} \cdot \mathrm{s}^{-1}$ it had dropped to $2 \%$. At $5 \mathrm{~m}^{3} \cdot \mathrm{s}^{-1}$ the concentration after $40 \mathrm{~d}$ was $<1 \%$ in the whole estuary.

\section{The effect of freshwater inflow on estuarine microalgae}

The water flow data referred to in this section represent actual measured values. The flow rates into the estuary ranged from 0.3 to $30.5 \mathrm{~m}^{3} \cdot \mathrm{s}^{-1}$. The sampling, from 25 October 1997 onwards was restricted to neap tides to reduce the number of variables affecting the REI. Average river flow for the period 7 November 1996 to 8 November 1998 was $25.6 \pm 5.9 \mathrm{~m}^{3} \cdot \mathrm{s}^{-1}$. This average includes the flood event of November 1996, when flow exceeded $3000 \mathrm{~m}^{3} \cdot \mathrm{s}^{-1}$ (Snow et al. 2000).

Phytoplankton chlorophyll- $a$ was unevenly distributed at low flow rates. The highest levels were within the upper half of the estuary at flow rates of $<2.3 \mathrm{~m}^{3} \cdot \mathrm{s}^{-1}$. At 9.7 and $30.5 \mathrm{~m}^{3} \cdot \mathrm{s}^{-1}$ chlorophyll- $a$ levels were low but well distributed throughout the estuary. Average phytoplankton chlorophyll- $a$ for the whole estuary was highest at flow rates of $0.8 \mathrm{~m}^{3} \cdot \mathrm{s}^{-1}\left(47.5 \pm 4.5 \mu \mathrm{g} \cdot \mathrm{l}^{-1}\right)$ and $1.2 \mathrm{~m}^{3} \cdot \mathrm{s}^{-1}$ $\left(49.9 \pm 7.3 \mu \mathrm{g} \cdot \mathrm{l}^{-1}\right)$. At higher flow rates $\left(>1.2 \mathrm{~m}^{3} \cdot \mathrm{s}^{-1}\right)$ chlorophyll$a$ decreased to $6.9 \pm\left. 0.6 \mu \mathrm{g} \cdot\right|^{-1}\left(30.5 \mathrm{~m}^{3} \cdot \mathrm{s}^{-1}\right)$, which was the lowest measured. A Pearson Product Moment Correlation showed that the overall relationship between phytoplankton chlorophyll- $a$ and flow was negative although not significant $(n=221$, Pearson's $r=$ $-0.70, \mathrm{P}=0.08)$. However, phytoplankton chlorophyll- $a$ increased from $27.1 \pm 6.9 \mu \mathrm{g} \cdot \mathrm{l}^{-1}$ to $47.5 \pm 4.5 \mu \mathrm{g} \cdot \mathrm{l}^{-1}$ as flow increased from 0.3 to $1.2 \mathrm{~m}^{3} \cdot \mathrm{s}^{-1}$. This positive relationship, although still not significant, $(\mathrm{n}=126$, Pearson's $\mathrm{r}=0.89, \mathrm{P}=0.11$ ) under low flow conditions corresponds well to results obtained from previous Eastern Cape studies (Hilmer and Bate 1991) where positive correlations between river input and phytoplankton chlorophyll- $a$ were found.

The highest mean vertical chlorophyll- $a$ value $\left(\left.115 \mu \mathrm{g} \cdot\right|^{-1}\right)$ was situated in the upper reaches (REI) of the estuary (>12 km from mouth) at a flow rate of $1 \mathrm{~m}^{3} \cdot \mathrm{s}^{-1}$. This maximum occurred in the same region of the estuary as the highest mean vertical nitrate concentration $(145 \mu \mathrm{M})$ at the same flow. Mineral nutrients (from the river and an agricultural field drainage pipe) and light are probably optimal for phytoplankton in the upper reaches of the estuary because of the lower volume and shallower water-column. The Student-Newman-Keuls multiple comparisons test showed that mean chlorophyll- $a$ in the upper reaches (>12 km; $62.4 \pm 11.9$ $\mu \mathrm{g} \cdot \mathrm{I}^{-1}$ ) was significantly higher than the mean middle (6 to $12 \mathrm{~km}$; $\left.28.1 \pm\left. 5.8 \mu \mathrm{g} \cdot\right|^{-1}\right)$ and lower reach $\left(<6 \mathrm{~km} ; 12.9 \pm\left. 3.5 \mu \mathrm{g} \cdot\right|^{-1}\right)$ values $(\mathrm{n}=19, \mathrm{P}<0.01)$. 
The attenuation of light through the water column was always greater near the head of the estuary compared to the mouth. The region of maximum turbidity for flow rates of $2.3 \mathrm{~m}^{3} \cdot \mathrm{s}^{-1}$ and lower was also the region of maximum phytoplankton chlorophyll- $a$, i.e. the REI region of the estuary. As flow increased from 0.3 to 30.5 $\mathrm{m}^{3} \cdot \mathrm{s}^{-1}$ the REI gradually shifted downstream from 16.5 to $6.8 \mathrm{~km}$ from the mouth. Chlorophyll- $a$ levels were well distributed at 9.7 and $30.5 \mathrm{~m}^{3} \cdot \mathrm{s}^{-1}$ making the position of the REI almost indistinguishable at these high flows.

Total benthic chlorophyll- $a$ biomass was calculated in relation to the total area for both the subtidal and intertidal regions. The Gamtoos Estuary is steep-sided with a narrow intertidal zone, hence the subtidal region makes up the largest area available for benthic microalgal establishment. Total intertidal $(8.7 \pm 0.1 \mathrm{~kg}$, average biomass $\left.=76.3 \pm 8 \mathrm{mg} \cdot \mathrm{m}^{-2}\right)$ and subtidal $(57.7 \pm 0.4 \mathrm{~kg}$, average biomass $=43.2 \pm 6.4 \mathrm{mg} \cdot \mathrm{m}^{-2}$ ) benthic chlorophyll- $a$ biomass values for the estuary reached their maximum at a flow of 1.16 and $1 \mathrm{~m}^{3} \cdot \mathrm{s}^{-1}$ respectively. Using a one-way ANOVA on ranks, these maxima were significantly higher (intertidal $n=162$, subtidal $\mathrm{n}=145, \mathrm{p}<0.0001)$ than the benthic chlorophyll- $a$ at all other flow rates. These data illustrate that while a recognisable REI exists within the estuary as far as phytoplankton are concerned, this does not include the benthic microalgal population. This latter population can only be differentiated into a small but rich intertidal population and a large but weaker subtidal population.

\section{The effect of freshwater inflow on estuarine invertebrates}

A steep salinity gradient along the main axis of the estuary was developed during all sampling series, ranging from near fullstrength seawater near the mouth to freshwater at the most landward sites. A significant feature was, however, that the freshwater wedge moved progressively seawards over time: in 1993 the landward limit of seawater intrusion was located $16.7 \mathrm{~km}$ from the estuary mouth, but in subsequent years freshwater penetrated a further $2.5 \mathrm{~km}$ downstream. There was very little gradation between the saline and fresh waters across the REI region. A sharp longitudinal halocline delineated the brackish from the saline reaches, with salinity at the bottom dropping from 12.5 to $\left.24.6 \mathrm{~g} \cdot\right|^{-1}$ to 0.1 to $0.5 \mathrm{~g} \cdot \mathrm{l}^{-1}$ over a distance of less than $2.5 \mathrm{~km}$.

\section{Longitudinal gradients in invertebrate density and diversity}

Distinct clines of abundance were evident for both the invertebrate components studied, but the direction of density change was in opposite directions for zooplankton and macrobenthos. Pelagic invertebrates tended to decline from the lower to the upper sections $\left(r_{s}=-0.31, p=0.25\right)$, whereas the density of benthic macrofauna rose with increasing distance from the sea $\left(r_{s}=0.49, p=0.09\right)$, attaining the highest abundance in waters of near zero salinity. By contrast, species richness showed a similar longitudinal gradient for both groups, with the number of taxa significantly decreasing towards the landward limit of tidal influence (plankton $r_{s}=-0.74$, $\mathrm{p}<0.01$; benthos $\mathrm{r}_{\mathrm{s}}=-0.70, \mathrm{p}=0.02$ ) (Wooldridge and Schlacher, 2002).

\section{Longitudinal patterns of invertebrate community structure}

Although community structure of benthic macrofauna showed a gradual change from the lower to the upper reaches, two zones stand out:
- Sediments near the estuary mouth harbour assemblages distinctly differ from the fauna of the remaining lower estuarine reaches. The boundary of this mouth region is located approximately $1.5 \mathrm{~km}$ from the estuary mouth.

- At the opposite end of the salinity range another distinct assemblage is restricted to within the REI region, the seaward boundary of this zone shifted between 14.0 and $17.0 \mathrm{~km}$, with the salinity always $<0.5 \mathrm{~g} \cdot \mathrm{l}^{-1}$. In the mesohaline middle reaches of the estuary, the macrofaunal zonation is more variable, but clear faunistic discontinuities delineate it (on both ends) from both the mouth section and the REI region.

No single species was found to be a perfect discriminator between the assemblage typical of the REI and the rest of the estuary, but the amphipod Corophium spp., the polychaete Desdemona ornata and Oligochaeta each contributed more than $8.0 \%$ to average dissimilarity between these two broad zones. Similarly, the same taxa contributed most to intra-group similarity and can therefore be regarded as being typical of this assemblage. Other species indicative of the REI community include the polychaete Ceratonereis keiskama and Chironomids. The fauna of the REI region appears, therefore, to be comprised of taxa normally affiliated to fluvial habitats (e.g. chironomids and oligochaetes) and a few estuarine taxa of exceptionally high physiological tolerance to low salinities (e.g. corophioid amphipods, some polychaetes).

Having identified the existence of a unique macrobenthos assemblage inhabiting the REI region, the question arises whether this community is of an ephemeral or permanent nature. The data showed that irrespective of sampling period, the same broad pattern of macrofaunal zonation developed along the salinity gradients with the distinct assemblages of the REI region being evident not only in each yearly plot but also clearly clustering into a definite group in an ordination of the combined data set. Thus, the basic nature of the macrobenthos assemblage in the REI zone is constant over time with a spatial range dependent on the freshwater inflow rate.

Zooplankton and macrobenthos community structure across the estuarine salinity gradient showed that each group also separated along the salinity gradient, i.e. zooplankton and macrobenthos assemblages at both the estuary mouth region and the REI region were distinct compared with communities in the middle section. The data for invertebrates thus indicate, in a similar manner to the microalgae, the existence of an REI region where distinct communities exist in response to salinity. It is interesting to note that while the macrobenthic faunal assemblages show a very clear salinity-dependent distribution, this does not coincide with a benthic microalgal food source because no such discontinuity was identified.

\section{The effect of freshwater inflow on fish assemblages}

Turbidity recorded in the Great Fish River and upper estuary, with means near 200 NTU, can only be described as highly turbid. Temperature varied between a minimum of $12^{\circ} \mathrm{C}$ in winter and a maximum of $29^{\circ} \mathrm{C}$ in summer. The ANOVA indicated a lack of significant differences between Sites 1 to 8 for either turbidity or temperature. Salinity, however, showed a significant difference ( $P$ $<0.01$ ) between sites and was therefore used as the parameter for differentiating between the regions. Measurements of $<1 \mathrm{~g} \cdot \cdot^{-1}$ were regarded as riverine, from 1 to $\left.4 \mathrm{~g} \cdot\right|^{-1}$ as the head of the estuary (REI) and $>4 \mathrm{~g} \cdot \mathrm{l}^{-1}$ as estuarine.

The average salinity in the Kariega Estuary was fairly constant (34 to $35 \mathrm{~g} \cdot \mathrm{I}^{-1}$ ) for the first 30 sites after which it dropped gradually 
to $23 \mathrm{~g} \cdot \mathrm{f}^{-1}$ at Site 39 . The only site that recorded salinities $<5 \mathrm{~g} \cdot \mathrm{f}^{-1}$ (oligohaline conditions) was Site 40 that had an average salinity of $3 \mathrm{~g} \cdot \mathrm{l}^{-1}$. Turbidity was generally low, ranging from 5 to $21 \mathrm{NTU}$. There were no clear trends, but the lowest turbidities were generally found in the mouth and headwater regions of the estuary.

Linking fish catches to Great Fish River volumes for the month before each sampling trip revealed distinct trends between flow rate and the species assemblage within the sampling area. Both Spearman's and Pearson's tests indicated a weak negative correlation between overall fish abundance and the riverine flow rate. Fish abundance in both the river and head regions decreased with increasing river flow, whereas the highest CPUE of fishes in the estuary was recorded during medium flow conditions. Under low flow regimes, the greatest abundance of fishes was recorded in the head region. With an increase in freshwater input the majority of fish species, especially the marine taxa, became scarce in the river. A major increase in river flow resulted in an overall decline in fish abundance throughout the system, with river flooding sometimes causing extensive fish mortalities in the estuary (Whitfield and Paterson, 1995).

The marine fish species contribution to the catch in the Great Fish River and estuary decreased from $>60 \%$ under low flow conditions to $<30 \%$ during periods of elevated riverine flow. Marine stragglers were absent from the river and were only present in small numbers in the estuary $(<0.1 \%$ of CPUE) during low or medium river-flow conditions. Estuarine species remained common under all flow regimes, whereas the catadromous and most of the freshwater species were more common during the elevated flow periods.

The translocated Orange River water has a major diluting effect on the Great Fish River water, with the latter having had extremely high conductivity levels before 1975 (O'Keeffe, 1989). Despite this dilution, conductivity levels in the system remain high (up to $625.0 \mathrm{mS} \cdot \mathrm{m}^{-1}$ ), except during river flooding when conductivity levels usually decline below $100 \mathrm{mS} \cdot \mathrm{m}^{-1}$. It is therefore likely that the abundance of marine and estuarine fishes in the river is closely related to conductivity, with declining fish abundance associated with reduced conductivity levels. Since most estuarine-associated fish species can tolerate freshwater conditions for short periods, the duration of flooding events has a major influence on the ichthyofauna (Marais, 1981). However, osmotic stress is not the only factor influencing estuarine fish survival during floods. For example, the extremely high suspensoid levels together with lowered dissolved oxygen concentrations during flash flooding in the Great Fish Estuary may have been responsible for the January 1995 fish kill in this system (Whitfield and Paterson, 1995). Since the definition of the head (REI) region and estuary was based on salinity and not geography, conductivity cannot be a factor affecting the abundance of fishes in these saline regions.

An inverse relationship is evident between river flow volume and conductivity. During periods of low water flow, salts leaching into the river cause an increase in conductivity, whereas high flow rates dilute this effect. Since sodium and chloride are two of the most prevalent elements in the Great Fish River, they also elicit the strongest response to dilution (Anonymous, 1995). It is probable that the reduction in their concentrations has an effect on the ability of euryhaline marine fishes to utilise the freshwater areas of the system. Under low- and medium-flow rates, the conductivity of the river water remains high, indicating the presence of significant amounts of salts. It is also under these conditions that euryhaline marine species dominate the catches $(>60 \%)$ in all three of the sampled regions. During and immediately after a flood the salts are diluted, conductivity decreases and the euryhaline marine species are no longer abundant in riverine samples. There is therefore an indirect link between river flow and marine fish distribution and abundance in the Great Fish River and REI region.

The geographical headwaters of the freshwater-deprived Kariega Estuary were utilised by a range of marine and estuarine fish species but, in contrast to the nearby freshwater-'rich' Great Fish Estuary, few important angling species (e.g. spotted grunter Pomadasys commersonnii and dusky kob Argyrosomus japonicus) were recorded. The reduced riverine flow into the Kariega Estuary resulted in an extremely restricted REI zone being made available to resident and migrant fish species. Despite the low freshwater flows recorded, the catadromous freshwater mullet Myxus capensis was abundant within the REI zone and headwater reach, possibly due to the lack of riverine habitat available for the juveniles of this species. Although salinity has been shown to be an important structuring force influencing ichthyofaunal assemblages in many South African estuaries, it was not the primary factor governing the distribution of fish in a freshwater-deprived, marine-dominated system such as the Kariega.

\section{Discussion}

The primary objective behind the research described here was to determine the value of the REI region in a permanently open estuary. In workshops held by the Department of Water Affairs and Forestry over the past few years, estuarine scientists have consistently maintained the opinion that freshwater is essential for the maintenance of biodiversity and productivity. However, no direct evidence was available to describe the importance quantitatively or to indicate the flow rates required to optimise productivity. Hilmer (1990) had shown that in the Sundays Estuary, a freshwater residence time of three spring tidal cycles resulted in the maximum primary productivity measured as standing phytoplankton biomass, but there was no evidence that high biomass of microalgae translated into similar responses in the invertebrate fauna and/or fish. This study was initiated to test the hypothesis that freshwater produced similar responses in all estuarine organisms.

During this study, there were a variety of river flow rates from ca. $0.2 \mathrm{~m}^{3} \cdot \mathrm{s}^{-1}$ to a flood estimated to be in excess of $3000 \mathrm{~m}^{3} \cdot \mathrm{s}^{-1}$. Having such a wide range to work with was very valuable and it was used to calibrate the MIKE 11 modelling system. Having been calibrated, the MIKE 11 model will be suitable for use in future estimates of the effect of river flow rate on salinity distribution in other estuaries.

An important finding from the simulation model was that there is very little difference in the salinity distribution between flood and ebb tides at neap tide. This means that the biological data collected at either flood or ebb at neap tide will most likely be applicable. The model results were also used to determine the volumes of water in the estuary below (and between) selected salinity levels of 5, 10, 15, 20, 25, 30 and $35 \mathrm{~g} \cdot \cdot^{-1}$ for different river flows. In this manner, the volume of available habitat (based on salinity) for aquatic organisms was calculated. This is a very important component when assessing the effect of river flow restriction because it allows an estimate of the extent of habitat decrease.

Calculations indicate that after a flood, the total volume of the Gamtoos Estuary was not greatly altered. The flood in 1996 scoured the upper channel and deposited much of the sediment in the lower reaches. This is contrary to the belief that a large flood scours out the whole estuary. What the data showed, however, is that the important REI region was greatly enlarged. 
The results of nutrient concentrations measured during this study have been reported by Scharler et al. (2002). Their results showed that although some nutrient species were found in higher concentration in the upper reaches $\left(<\left.17 \mathrm{~g} \cdot\right|^{-1}\right)$, it was not possible to identify, through mineral elements, the REI as a region with elevated mineral status. In general, concentrations of nitrate, nitrite, dissolved organic carbon (DOC) and nitrogen (DON), particulate organic nitrogen (PON) and total particulate phosphorus (TPP) decreased towards the mouth. On reflection, it is perhaps not surprising that a zone of elevated mineral nutrients did not identify the productive REI. As the mineral nutrient supply from freshwater enters the estuary, it is likely taken up by phytoplankton very rapidly. At the same time, however, excretion of consumed minerals would enter the water column as organic forms and be mineralised. This would then be taken up again by phytoplankton and the cycle would repeat. At the mouth, minerals would be exported to sea as fauna and, together with dilution by sea water, the measurable nutrient level in the water would be low.

The concentration of nitrate and nitrite in the water within the sediment was 5 to 10 times higher than in the water column, but no concentration gradient existed between the water and sediment for ammonium or phosphate (Scharler et al., 2002). Nitrate, nitrite, and ammonium in sediment water were significantly correlated with respective concentrations in the deep water $(0.58, \mathrm{p}<0.001 ; 0.24$, $\mathrm{p}<0.05 ;-0.26, \mathrm{p}<0.05$, respectively). Both sediment water and deep-water phosphate concentrations were very low in the Gamtoos Estuary. This indicates a phosphate-limited environment. These findings suggest that sediment water nutrients are a non-point source to the water column throughout the estuary.

The microalgal study in the Gamtoos Estuary showed that the highest biomass resulted from a base flow of $c a \cdot 1 \mathrm{~m}^{3} \cdot \mathrm{s}^{-1}$. Below and above that flow rate, the total estuarine biomass and phytoplankton concentration was reduced. As the flow rate increased, so the vertically averaged salinity (10 to $\left.15 \mathrm{~g} \cdot \cdot^{-1}\right)$ of the water column moved down towards the mouth. The chlorophyll- $a$ maximum in the estuary was consistently located in or near the 10 to $15 \mathrm{~g} \cdot \mathrm{f}^{-1}$ salinity range. Bate and Adams (2000) showed in the nearby Kromme Estuary that a continuous base flow is important rather than the introduction of a single pulse of freshwater. It is important to appreciate, however, that estuaries do not necessarily function naturally at the optimum flow rate to produce the maximum microalgal biomass and productivity. Presumably, those that function naturally at or near the optimum flow rate are classified as 'very productive'.

In channel-like freshwater rich estuaries such as the Gamtoos and Sundays, estuarine endemic zooplankters attain very high biomass levels (Wooldridge, 1999). Copepods, and in particular e.g. Pseudodiaptomus hessei, attain their maximum abundance in the mesohaline ( 10 to $15 \mathrm{~g} \cdot \mathrm{l}^{-1}$ ) region where the phytoplankton food source is readily available.

Pelagic and benthic assemblages of invertebrates in the low salinity REI region had a different species composition and abundance to those found in more saline estuarine reaches. The invertebrate communities found in regions of low salinity were distinct in their biological structure.

Benthic communities of the REI are not only unique in their biological structure but display a different trophic organisation compared with more saline down stream waters: filter-feeding forms dominate the assemblages of low-salinity regions, possibly as a response to the high phytoplankton production in this region.

Different salinity reaches have different carbon signatures (i.e. stable isotope ratios) in comparison to other areas in the estuary (Schlacher and Wooldridge, 1996b). The zooplankton in the REI zone show strong links to the phytoplankton signature in the Gamtoos Estuary. Similarly, other organisms utilising either phytoor zooplankton as a food source in the REI region show affinities to these highly negative carbon signatures. Conversely, the benthic microalgal community fuels a different food web.

The similar and systematic variation in carbon composition across the salinity spectrum in both producers and consumer groups, suggests that production and consumption of organic matter are coupled on a local scale. Localised processing of energy through the food web within a salinity zone may override transport and mixing of organic matter between salinity zones. This highlights the importance of the REI zone as a unique habitat supporting specific communities associated with that habitat.

The evidence suggests that river flow has a major impact on the structure and functioning of fish communities within estuaries and especially in the upper reaches or REI region. The high conductivity of the Great Fish River water resulted in both the river and headwater regions of the estuary being utilised by euryhaline marine and estuarine fish species. Those marine species that have been shown to be dependent on estuaries as nursery areas tended to move furthest up the Great Fish system, often into the river itself.

Of particular significance were the large numbers of juveniles of the spotted grunter (Pomadasys commersonnii) and dusky kob (Argyrosomus japonicus) that utilise the REI region of the Great Fish system as a primary nursery area. These two species are especially important as recreational fish. Thus, the financial importance of the REI can be directly linked to the adequate provision of freshwater. During and immediately after a flood in the Great Fish River catchment, the conductivity of water flowing into the estuary decreased and, under these circumstances, the euryhaline marine species were no longer abundant in riverine samples. Hence, the quality of freshwater that will in future be permitted to flow into estuaries will have an influence on the structure of fish communities. This type of influence must be taken into account when allocating water to estuaries and especially water rising in arid areas such as the Karoo, e.g. the Gamtoos Estuary.

The geographical headwaters of the freshwater-deprived Kariega Estuary were utilised by a range of fish species but, in contrast to the Great Fish Estuary, few important recreational or subsistence species (e.g. P. commersonnii and A. japonicus) were recorded. This restricted riverine flow into the Kariega Estuary resulted in a much smaller REI area being available for resident and migrant fish species. This is further evidence for the importance of freshwater in natural estuarine function.

The research reported here succeeded in establishing that freshwater is important if estuaries are to maintain their natural function. The importance has been demonstrated for microalgae, invertebrates and fish. Not only is the strength of the REI determined by freshwater inflow quality, but also the size of the REI is influenced by both rate of base flow and periodical flooding. However, when attempting to determine the quantity and quality of freshwater required, it will be necessary to take into account a number of factors that will be estuary specific. For example, if a river flows through an area prone to droughts, the amount of water supplied should be adjusted accordingly. Likewise, if the wave climate at sea is high such that the mouth tends to close easily that feature must be included in the decision-making process. Similarly, if the river flows through a region yielding a high salt load from the geology, the amount and quality of water provided in terms of the Water Act should be adjusted to provide for the faunal populations that occurred naturally. The point being made is that it is not possible in the case of estuaries to derive a formula that can be 
applied to all estuaries. Decisions will have to continue to be made based on available information and experience.

\section{Acknowledgements}

The Consortium for Estuarine Research and Management undertook this project. The physical data and the MIKE 11 modelling was led by Mr Piet Huizinga, while water chemistry data were accumulated mainly by Miss Ursula Scharler and Professor Dan Baird. Mr Gavin Snow used the microalgal research as part of his M.Sc. programme with Dr Janine Adams and Professor Guy Bate. Professor Tris Wooldridge led the invertebrate study, while Dr Alan Whitfield led the work on fish in the Kariega and Great Fish Estuaries. Members of the CSIR, the University of Port Elizabeth and the South African Institute for Aquatic Biodiversity provided laboratory assistance. The project was managed by Mrs Jenny Mander of the Institute of Natural Resources, University of Natal, and Pietermaritzburg and funded by the Water Research Commission.

\section{References}

ALLANSON BR and READ GHL (1995) Further comment on the response of Eastern Cape Province estuaries to variable freshwater inflows. S. Afr. J. Aquat. Sci. 21(1/2) 56-70.

ANONYMOUS (1995) Rivers of southern Africa: The Great Fish River. Afr. Wildl. 49 (5) 15.

BATE GC and ADAMS JB (2000) The effects of a single freshwater release into the Kromme Estuary. 5. Overview and interpretation for the future. Water SA 26 329-332.

GRANGE N (1992) The Influence of Contrasting Freshwater Inflows on the Feeding Ecology and Food Resources of Zooplankton in Two Eastern Cape Estuaries, South Africa. Ph.D. Thesis, Rhodes Univ., Grahamstown. 230 pp.

GRANGE N and ALLANSON BR (1995) The influence of freshwater inflow on the nature, amount and distribution of seston in estuaries in the eastern Cape, South Africa. Estuarine, Coastal and Shelf Sci. 40 403-420.

GRANGE N, WHITFIELD AK, DE VILLIERS CJ and ALLANSON BR (2000) The response of two South African estuaries to altered river flow regimes. Aquat. Conserv.: Mar. and Freshwater Ecosyst. 10 $155-177$.

HANEKOM N, BAIRD D and ERASMUS T (1988) A quantitative study to assess standing biomasses of macrobenthos in soft substrata of the Swartkops Estuary, South Africa. S. Afr. J. Mar. Sci. 6 163-174.

HILMER T (1990) Factors Influencing the Estimation of Primary Production in Small Estuaries. Ph.D. Thesis, Dept of Botany, Univ. of Port Elizabeth.

HODGSON AN (1987) Distribution and abundance of the macrobenthic fauna of the Kariega Estuary. S. Afr. J. Zool. 22 153-162.
JEZEWSKI WA and ROBERTS CPR (1986) Estuarine and Lake Freshwater Requirements. Dept of Water Affairs, Technical Report No. TR129iv, Pretoria. 22 pp.

LAURENSON LJB (1984) Colonisation Theory and Invasive Biota: The Great Fish River, a Case History. M.Sc. Thesis, Rhodes Univ., Grahamstown.

MARAIS JFK (1981) Seasonal abundance, distribution, and catch per unit effort using gill nets, of fishes in the Sundays estuary. S. Afr. J. Zool. 16 144-150.

O' KEEFFE JH (1989) Conserving rivers in southern Africa. Biol. Conserv. 49 255-274.

O'KEEFFE JH and DE MOOR FC (1988) Changes in the physicochemistry and benthic invertebrates of the Great Fish River, South Africa, following an interbasin transfer of water. Regulated Rivers Res. and Manage. 2 (1) 39-55.

NUSCH EA (1980) Comparison of different methods for chlorophyll and phaeopigment determination. Archiv für Hydrobiol., Beiheft Ergebnise der Limnol. 14 14-36.

REDDERING JSV and ESTERHUYSEN K (1982) Fluvial Dominated Sedimentation in the Great Fish Estuary. Dept of Geol., Univ. of Port Elizabeth, ROSIE Report No. 4. 62 pp.

SCHLACHER TA and WOOLDRIDGE TH (1996a) Axial zonation patterns of subtidal macrozoobenthos in the Gamtoos Estuary, South Africa. Estuaries 19 (3) 680-696.

SCHLACHER TA and WOOLDRIDGE TH (1996b) Origin and trophic importance of detritus - evidence from the stable isotopes in the benthos of a small, temperate estuary. Oecologia 106 382-388.

SCHARLER U, BAIRD D, ASTILL H and ADAMS J (2002) Water column and benthic nutrient status in and around the river-estuary interface (REI) zone of the Gamtoos Estuary. In: Whitfield AK and Wood AD (eds.) Studies on the River-Estuary Interface Region of Selected Eastern Cape Estuaries. Water Research Commission Report No 756/2/02. 314 pp.

SLINGER JH, TALJAARD S, ROSSOUW M and HUIZINGA P (1998) Water Quality Modelling of Estuaries. Water Research Commission Report No. 664/1/98. 110 pp. + Appendices.

SNOW GC, ADAMS JB and BATE GC (2000) Effect of river flow on estuarine microalgal biomass and distribution. Estuarine, Coastal and Shelf Science 51 255-266.

WHITFIELD AK and PATERSON AW (1995) Flood-associated mass mortality of fishes in the Sundays Estuary. Water SA 21 (4) 385-389.

WHITFIELD AK and WOOD AD (eds.) (2002) Studies on the RiverEstuary Interface Region of Selected Eastern Cape Estuaries. Water Research Commission Report No 756/2/02. 314 pp.

WOOLDRIDGE TH (1999) Estuarine zooplankton community structure and dynamics. In: BR Allanson and D Baird (eds.). Chapter 7. Estuaries of South Africa. Cambridge Univ. Press. 141-166.

WOOLDRIDGE TH and SCHLACHER TA (2002) Structure and dynamics of the invertebrate component within the river-estuary interface (REI) region of the Gamtoos Estuary (Chapter 5). In: Whitfield AK and Wood AD (eds.) Studies on the River-Estuary Interface Region of Selected Eastern Cape Estuaries. Water Research Commission Report No 756/2/02. 314 pp. 
